\title{
Guidance and Ethical Considerations for Undertaking Transgender Health Research and Institutional Review Boards Adjudicating this Research
}

\author{
Noah Adams, ${ }^{1, *}$ Ruth Pearce, ${ }^{2, \dagger}$ Jaimie Veale, ${ }^{3}$ Asa Radix ${ }^{4,5}$ Danielle Castro, ${ }^{6}$ Amrita Sarkar, ${ }^{7,8}$ and Kai Cheng Thom ${ }^{9}$
}

\begin{abstract}
The purpose of this review is to create a set of provisional criteria for Institutional Review Boards (IRBs) to refer to when assessing the ethical orientation of transgender health research proposals. We began by searching for literature on this topic using databases and the reference lists of key articles, resulting in a preliminary set of criteria. We then collaborated to develop the following nine guidelines: (1) Whenever possible, research should be grounded, from inception to dissemination, in a meaningful collaboration with community stakeholders; (2) language and framing of transgender health research should be non-stigmatizing; (3) research should be disseminated back to the community; (4) the diversity of the transgender and gender diverse (TGGD) community should be accurately reflected and sensitively reflected; (5) informed consent must be meaningful, without coercion or undue influence; (6) the protection of participant confidentiality should be paramount; (7) alternative consent procedures should be considered for TGGD minors; (8) research should align with current professional standards that refute conversion, reorientation, or reparative therapy; and (9) IRBs should guard against the temptation to avoid, limit, or delay research on this subject.
\end{abstract}

Keywords: community participation; privacy; research ethics; transgender

\section{Introduction}

Institutional Review Boards (IRBs) exist to protect the rights and welfare of potential study participants and to ensure that research is conducted in an ethical manner. A favorable IRB review is typically an absolute requirement for conducting academic and institutional research with human participants. However, a diverse spectrum of research is submitted to these panels and board members are required to have, or quickly find, expertise in an array of topics, which can be challenging. ${ }^{1}$

This article outlines nine criteria, grounded in a review of the ethical and methodological literature in this field, to assist IRBs in assessing research projects on transgender health and especially those that involve transgender and gender diverse (TGGD) participants. These criteria may also be helpful to individual researchers, practitioners, and other professional entities responsible for evaluating research involving transgender health and TGGD participants. In particular, the authors hope that they will contribute to the groundwork preceding the creation of a section on the ethical conduct of research in the forthcoming eighth edition of the World Professional Association for Transgender Health (WPATH) Standards of Care

\footnotetext{
${ }^{1}$ Faculty of Health Professions, School of Social Work, Dalhousie University, Halifax, Nova Scotia, Canada.

${ }^{2}$ Department of Sociology, University of Warwick, Coventry, United Kingdom.

${ }^{3}$ Department of Psychology, University of Waikato, Hamilton, New Zealand.

${ }^{4}$ Callen-Lorde Community Health Center, New York, New York.

${ }^{5}$ New York University School of Medicine, New York, New York.

${ }^{6}$ Center of Excellence for Transgender Health, University of California San Francisco, San Francisco, California.

${ }^{7}$ IRGT, A Global Network of Trans Women and HIV, Oakland, California.

${ }^{8}$ Solidarity and Action Against HIV Infection in India, New Delhi, India.

${ }^{9}$ Central Toronto Youth Services, Toronto, Canada.

'Current address: School of Sociology and Social Policy, University of Leeds, Leeds, United Kingdom.

*Address correspondence to: Noah Adams, MSW, E-mail: noah@noahjadams.com
} 
for the Health of Transsexual, Transgender, and Gender Nonconforming People.

\section{Background}

Transgender healthcare is a rapidly growing field, with an exponential increase in research published in recent years. ${ }^{2}$ Within this field there is a small but growing literature providing guidance on ethical issues in research involving TGGD individuals. Although some of this literature is intended for a wider audience, including IRBs, individual researchers, and clinical practitioners, we located three articles presenting specific guidelines to IRBs for research with TGGD individuals and communities. ${ }^{3-5}$ This article synthesizes these previous recommendations, additional relevant literature, and the expert opinion of its authors into a cohesive set of guidelines for IRBs adjudicating transgender health research. We hope they will also prove helpful to individual researchers, practitioners, and professional organizations.

\section{Methodology}

In developing the criteria outlined in this article, the lead author undertook a comprehensive review of the academic literature to identify relevant sources. Searches were conducted for English-language literature on Google, Google Scholar, and WorldCat by using the keywords "transgend ${ }^{*}$," "transsex ${ }^{\star}$," "gender divers ${ }^{\star}$," "Institutional Review Board," "Research Ethics Board," "Research Ethics Committee," and "guidance," and reference lists of key articles were also examined. A preliminary version of criteria for IRBs adjudicating transgender health research was developed based on this literature. Transgender health researchers from a variety of different backgrounds were then contacted to collaborate and co-author the final set of criteria. This ensured that knowledge and experience from a diverse range of national and social contexts was taken into consideration in this process.

\section{Areas of Concern}

Within the field of transgender healthcare research, areas identified as particularly important for ethically and methodologically sound research include definitions of risk and harm, differences between practice and research, and situations requiring (or not requiring) anonymity. ${ }^{6-8}$ Also of serious concern is that, despite extreme marginalization and violence faced by TGGD individuals, no research on the application of ethical standards in this population exists within social and psychological research. ${ }^{4,9}$ The history of this field, intersectionality, and researchers' linguistic choices all play an important role in the current state of ethics in this field and, thus, what these guidelines aim at addressing.

\section{Historical}

Transgender health research and practice has not always been sensitive to the humanity of either individual TGGD participants or the larger community. ${ }^{4}$ Some examples include the pathologizing approach taken by influential works such as Psychopathia Transsexualis, ${ }^{10}$ The Sissy Boy Syndrome ${ }^{11}$ and more recent research into the attractiveness of TGGD children. ${ }^{12}$ More generally, transgender health research has and continues to tend toward representing TGGD people as homogenous and lacking diversity in areas such as, but not limited to, ethnicity, gender identity, and sexuality. ${ }^{5,13-16}$ The publication of the first edition of the WPATH Standards of Care ${ }^{17}$ addressed some of these issues and sought to protect both clients and medical professionals by providing guidance on the treatment and management of TGGD clients. Unfortunately, these standards have failed to explicitly outline the ethical conduct of research, which is worrying as some is conducted in a manner that precludes proper consent and skirts the line of exploitation, as when patients are required to participate in research as a condition of treatment. ${ }^{5,13,18-20}$

\section{Intersectionality}

Intersectional theory recognizes that particular experiences and challenges arise at the intersection of multiple axes of oppression, and it advises researchers to be mindful of the unique experiences (and vulnerabilities) of individuals experiencing these intersecting oppressions. For example, Crenshaw ${ }^{21}$ notes that the challenges faced by black women are more than the sum of racism and sexism; similarly, black transgender women encounter specific experiences at the intersection of racist, cisgenderist, and sexist social forces. ${ }^{22,23}$ Unfortunately, though intersectionality is frequently discussed within social sciences and humanities transgender studies scholarship, ${ }^{24-29}$ except in some Western contexts where research is explicitly undertaken with TGGD people of color, ${ }^{30-32}$ it is rarely present in the literature on transgender health. Despite this, acknowledging and accounting for intersectional experiences can strengthen ethical frameworks for healthcare research and 
practices, enhance analyses of difference within TGGD populations, and ensure the external validity of results. ${ }^{31-34}$ Consequently, we integrated an intersectional approach into formulating and explaining our proposed criteria.

\section{Language}

Researchers' choices of terminology may degrade both the efficacy of their studies and community trust. For example, by referring to TGGD women as "male transsexuals" ${ }^{\prime 3,35}$ researchers risk alienating participants and increasing distrust of researchers within trans communities. In the longer term, this can cause difficulties for the future recruitment and development of trust with participants. ${ }^{19,36,37}$ As a result, it is often necessary to establish trust with TGGD participants before it is possible to gather accurate data. This is particularly the case when research is conducted in environments that also provide transgender healthcare, or on topics that are especially controversial (e.g., the provision of services for gender nonconforming children). ${ }^{4,19}$

In this article, the authors have used TGGD, rather than transgender and gender nonconforming (TGNC), to describe the population being discussed. Though TGNC is more frequently used in the literature, it does not appear to be an appropriate or inclusive term for our purposes. ${ }^{33}$ In many cultures, particularly the Global South and Indigenous/Two-Spirit populations, transgender is not a default term used to identify genders outside female and male and it may, for this reason, exclude individuals outside of these contexts. ${ }^{38-40}$

We have also included a glossary, which should be of use to those less familiar with this language, identifying and defining the basic transgender healthcare terminology used in this article (Appendix 1). However, the nature of language on transgender health and experience is that it is continuously shifting and researchers are, therefore, advised to update their familiarity with it through informed Internet searches and contact with TGGD organizations. ${ }^{5,35}$ In addition, although this glossary may be a helpful starting point for ensuring that research projects are nondiscriminatory, it should be used in an advisory, rather than prescriptive fashion.

\section{Criteria}

We propose the following nine criteria for IRBs to use in considering research proposals on transgender health. We hope that they will also be helpful in advising individual researchers, practitioners, and organizations.
However, when putting them into use, please note that these broad guidelines are not definitive and that examples are illustrative rather than exhaustive.

Whenever possible, research should be grounded, from inception to dissemination, in a meaningful collaboration with community stakeholders

IRBs should consider whether researchers have appropriately built, or indicated how they will build, links with community stakeholders. Failing to meaningfully incorporate TGGD participation into research can result in silencing participants, particularly those who experience complex and intersecting forms of marginalization. ${ }^{15,20}$ This may result in these individuals becoming more invisible and difficult to reach, compounding the absence of their voices and narratives in research. ${ }^{8,14,41}$ Failure to adequately engage with TGGD individuals and communities may also increase the risk of reporting inaccurate results; for example, ignorance of culturally specific TGGD language may result in errors in sampling. ${ }^{33,34}$

IRBs might advise that researchers form and consult with a community advisory board, consisting of a diverse TGGD membership, which "reflects the specific communities at the center of the research question." Community-based participatory research models also offer opportunities for mutually beneficial and transformative collaborative partnerships between those who fund, sponsor, and implement research, and the groups, individuals, and communities affected by it. ${ }^{42-44}$ These partnerships aid in the development of surveys and interview questionnaires, provide an opportunity for marginalized voices to emerge, improve access to and participant retention, and allow researchers to benefit from extensive TGGD in-group knowledge. ${ }^{4,7,19,45-48}$ Regardless of these, all researchers will benefit from spending personal time in the TGGD community, both to foster familiarity and trust and to be available to receive feedback and suggestions personally. ${ }^{5}$

The participation of TGGD-identified individuals in the research team, particularly as principal or coinvestigators, also creates a number of unique challenges that should be directly addressed. Primary among these are potential bias, blind spots, and interpersonal factors. ${ }^{19,45}$ Dual relationships may be particularly difficult to avoid due to complex and extended interpersonal, professional, and clinical networks linking researchers, practitioners, clients, and TGGD communities. ${ }^{4,19}$ However, provided they are neither sexual 
nor exploitative, these relationships are not inherently problematic and may even help to obtain access to and build trust with participants. ${ }^{19,36}$ Insider researchers, in particular, may have fewer hurdles to overcome mistrust between researchers and marginalized communities and, thus, to effectively access and develop alliances with these populations. ${ }^{19,36,49}$

Nevertheless, dual relationships can cause problems; for example, where research participants are concerned about sharing highly personal information with those in their social and community networks, they can inhibit disclosure. IRBs might, therefore, consider advising researchers to anticipate the need for diligent supervision and diagramming plans for dealing with these issues before they arise. Such plans might include disclosing preexisting personal or professional relationships between researchers and participants and assigning interviews to individuals who do not have this relationship. ${ }^{19}$ More generally, researchers should engage in reflexivity (self-reflection and accountability) and maintain an awareness of the potential for power differentials and relationship dynamics between participants and themselves, regardless of shared experience. $^{36,50}$

Language and framing of research

should be non-stigmatizing

IRBs should be aware, in scrutinizing proposals, that linguistic choices may both support and oppose TGGD stigma. ${ }^{4,5,13}$ Language that unnecessarily pathologizes or passes moral judgment can cause harm to participants both during the research process and on publication of findings. ${ }^{13,51}$ Bouman et al. ${ }^{35}$ discuss this topic in detail, and some basic guidance on this can be found in Appendix 1. We will outline here how this relates to transgender health research, how IRBs might best respond to this concern, and some additional factors that they should keep in mind when approaching this topic. Ultimately, however, the best way to ensure the use of appropriate language in research with TGGD individuals is through the involvement of community stakeholders (see Criterion "Whenever possible, research should be grounded, from inception to dissemination, in a meaningful collaboration with community stakeholders").

TGGD identities and behavior should not be described as necessarily pathological. It is, for example, unhelpful for researchers to imply that TGGD experiences are inextricably linked to "social and developmental problems," ${ }^{45}$ or to describe TGGD gender identities as "'extreme', 'persistent', or 'comorbid"13 with other conditions. Care should also be taken not to de-gender, misgender, or contradict participants' selfidentified gender, label it as inauthentic, or overemphasize the gender that participants were designated at birth (e.g., by describing someone as a biological, natal, or normal woman or man). ${ }^{35,52,53}$

IRBs might respond to this by advising researchers to include questionnaire and survey options that reflect genders outside of the male/female binary, as in the two-step method outlined in the discussion of Criterion "The diversity of the transgender and gender diverse community should be accurately and sensitively reflected" later. ${ }^{35,52,53}$ They might also advise that gender-based comparisons be parallel; for example, by comparing transgender men with cisgender men, not with "normal" or "typical" women or men., 45 There may be instances where comparison on the basis of assigned sex is warranted in some biologically focused research (e.g., research of cancer), but these comparisons should be justified and discussed by using sensitive language. ${ }^{35,54}$

IRBs should advise researchers to take care in framing their research in a manner that positively impacts TGGD individuals and their community and minimizes its potential utility for harm. ${ }^{4,5}$ Tannehill $^{55}$ provides an excellent synopsis of how research has been misused and misinterpreted in support of harmful policies and laws directed at TGGD individuals and communities. Topics of particular risk include research on suicidality and poor mental health outcomes, ${ }^{35,56}$ autogynephilia, ${ }^{57}$ and the persistence of TGGD identities from childhood into adulthood. ${ }^{58}$ Although researchers working in these areas may not intend for their findings to be used in a harmful manner, their work can, nevertheless, be employed to advance anti-TGGD dogma, attack the provision of transgender healthcare, and increase stigma. IRBs might advise that some researchers have sought to mitigate and challenge the misuse of their findings through collaboration with TGGD individuals and communities and by actively engaging with the media to establish the intended interpretation of their findings. $55,59,60$

\section{Research should be disseminated}

back to the community

The field of transgender healthcare has sometimes appeared to prioritize research that is individually and theoretically interesting over that which might have concrete benefits for, be actively disseminated 
to, or include TGGD communities. ${ }^{5,50}$ Well-designed and accessible research can, however, be of immense benefit to TGGD community organizations, health professionals, and policy makers. ${ }^{15,20,37,44}$ IRBs should, therefore, address the manner in which individual projects plan to locate, write about, conceptualize, interpret, and disseminate findings from extremely marginalized groups in a way that is meaningful to and inclusive of these communities. ${ }^{5,43,61}$

Ideally, researchers will have identified a plan for making their findings accessible to TGGD communities and non-academic healthcare professionals in their IRB proposal. For instance, if they are applying for a grant, they may have budgeted for open access publication and dissemination of findings through digital and traditional media. IRBs might also encourage researchers to include a provision in their proposal that commits them to sharing their findings via alternative mediums that appeal to wider audiences, such as community reports, online videos, blogs, and postcards. ${ }^{42,62-64}$

\section{The diversity of the TGGD community}

should be accurately and sensitively reflected

IRBs are advised to consider whether research proposals indicate an appropriate awareness of TGGD diversity and culture. Researchers should be expected to demonstrate that they are open to a process of reflexive, ongoing learning, in recognition of the multiplicity and fluidity of TGGD identities, experiences, politics, and cultures. ${ }^{8,35,65}$ This is particularly important for proposals that involve white/Western researchers undertaking studies in the Global South and/or with Indigenous/Two-Spirit populations. ${ }^{66}$ Such projects run the risk of erasing or rendering invisible traditional Indigenous concepts of gender, especially those that normalize forms of non-binary gender expression, ${ }^{13,42,67}$ in favor of Western ones, as in the term transgender. ${ }^{14,68}$

IRBs can test for an awareness of TGGD diversity by, for example, scrutinizing the proposed methods for obtaining information on gender identity. In doing so, IRBs might notice a tendency to reflect the gender identity of TGGD individuals as homogenous, ${ }^{18}$ through a medical or disease-based lens, ${ }^{16,42,69}$ and in binary terms (e.g., either or neither male nor female) ${ }^{5,70}$ Though piloted and largely deployed in Western research environments, the two-step method, ${ }^{71,72}$ which involves asking participants to (1) describe their gender identity and (2) identify the sex they were assigned at birth, ${ }^{73}$ has been successfully used in a variety of international contexts to accurately reflect the diversity of TGGD gender identities. ${ }^{74}$ Further, this method includes individuals who do not identify as $\mathrm{TGGD}^{5}$ and can be adapted to incorporate non-binary individuals through the addition of vectors such as "female-to-other" and "male-to-other" and/or by allowing participants to select and write in multiple gender options, including " $X$ " or non-binary, simultaneously. ${ }^{75-77}$ In addition, some research has tended to conflate intersex and TGGD participants ${ }^{48,78}$ and IRBs may advise that researchers provide a definition of these terms as a precursor to asking participants whether they fit them. "Intersex" should also be selectable separately and in addition to gender identity. ${ }^{62}$

Further methodological issues include the use of instruments that are validated with non-TGGD populations, presume participant heterosexuality, ${ }^{80}$ conflate gender identity and sexual orientation, ${ }^{80}$ ask respondents to comment on sexual acts they cannot perform due to their genital configurations, ${ }^{7}$ or assume that all TGGD individuals desire or require surgical interventions. ${ }^{9,56,81}$ These biases may find expression in the theories and framings underpinning research questions, sampling, instruments, and data analysis and IRBs should seek to ensure that they are not reflected in the proposals before them. ${ }^{4}$ For example, although Internet samples are favored in accessing hidden populations, ${ }^{42}$ this method is also strongly correlated with overwhelmingly white and highly educated samples. In-person data collection, on the other hand, tends to garner higher responses from individuals who are rural, older, less educated, poor, and/or people of color. ${ }^{42}$ Although not always possible, researchers should be supported in efforts to combine these methods.

Finally, IRBs may need to remind researchers that, where research is potentially distressing, they are obliged to refer participants to culturally suitable crisis and social services. These may include suicide crisis hotlines, housing and shelters, employment programs, behavioral and medical care, and other services that are specific to the needs of local TGGD communities. Unfortunately, many such resources may be culturally inclusive in some aspects without meeting all the needs of TGGD participants. This may even be the case with services generally targeted at the LGBT community. In addition, such services are often plentiful in some areas and scarce in others. Examples of appropriate resources 
include Trans Lifeline in North America and Switchboard LGBT+ Helpline in the United Kingdom. Researchers should collaborate with their local TGGD community to identify others.

Informed consent must be meaningful, without coercion or undue influence

IRBs are advised to ensure that robust informed consent procedures are in place for TGGD research and information on this process explicitly available to potential participants. Unfortunately, it is not clear whether informed consent is universally or consistently applied in the field of transgender healthcare research, particularly when this research originates in healthcare settings that are also the only available source of transitional services. ${ }^{16,20}$ Consenting to participate in research in these environments may involve providing extraordinary levels of personal information and agreeing to unlimited follow-up, under the real or imagined fear that refusal to consent could result in a denial of healthcare services. ${ }^{16,20,36,82}$ Ultimately, properly informed consent may not be possible if individuals perceive that refusal to participate will jeopardize their access to care. ${ }^{5,20}$

IRBs should ensure that researchers qualify the barriers and limitations to consent inherent in their research, clarify how participants can refuse to participate or withdraw their consent at any time, ${ }^{4}$ and inform participants of the meaning and purpose of the research. In the case of research conducted in a clinical setting, it is particularly important to assure participants, both verbally and in all written communication and consent forms, that any provision of transgender healthcare is also available in a manner that is explicitly independent of research participation. ${ }^{4,16}$ In all such communication, care should also be given to such factors as literacy and familiarity with medical and academic terminology. ${ }^{4}$ Further, in designating a point of contact for concerns or enquiries, an alternative should be provided for individuals whose primary physician is named.

The protection of participant confidentiality

should be paramount

Though standard in most IRB protocols, IRBs should take particular care in ensuring that researchers working with TGGD populations protect participant confidentiality, as this research may involve the collection of extremely sensitive data that could place participants at serious personal risk. ${ }^{8}$ Particularly as, "for some
[TGGD] people, providing basic demographic information [e.g., gender, race, zip code] is sufficient to identity" them. ${ }^{8}$ Research on this topic must, therefore, take the highest precautions to ensure and protect participants' privacy, confidentiality, and, unless otherwise explicitly agreed on, anonymity. Anonymity can be protected in a variety of fashions, such as employing identification codes, retaining data in secure storage, and/or letting participants create and remember their own unique identifiers. ${ }^{4}$

IRBs might recommend the use of various other tools for protecting participant anonymity, confidentiality, and/or ensuring consent. For example, data collection can occur online, via survey instruments hosted on associated university servers and stored offline under encryption, or it can be completed anonymously on paper, with consent explicitly implied by filling out and returning the survey. ${ }^{4}$ IRBs may also suggest that researchers proactively guard against the risk of data being requested in legal proceedings by seeking the local equivalent of a United States Certificate of Confidentiality from the U.S. Public Health Service. ${ }^{4}$ Finally, recruitment registries, though invaluable, ${ }^{44}$ should always be opt-in only and employed cautiously, due to the potential for privacy violations and misrepresentation of the information collected. The data captured in these registries are static, whereas individual identities, behaviors, and attractions are not.

IRBs should note that although it must never be forced, there are circumstances in which participants may want to eschew their anonymity. For instance, some research focuses on critically examining publicly available materials created by TGGD people, such as blogs, news articles, and social media videos. It can, in these cases, be appropriate to cite the authors of these works so as to amplify voices and perspectives that may otherwise be silenced or erased within research contexts. ${ }^{15,36}$ More generally, anonymization should be a process based on informed consent, rather than a "one size fits all" approach. ${ }^{83,84}$

\section{Alternative consent procedures}

should be considered for TGGD minors

Parental or guardian consent has long been seen as an absolute rule when conducting research with minors. ${ }^{85}$ However, IRBs are advised that, to avoid excluding or pressuring youth who have not disclosed their gender identity to their family, some researchers may employ alternative approaches to consent with TGGD minors. ${ }^{8,86-88}$ IRBs should judge these approaches on 
their merits and within the context of the particular scenario. For instance, IRBs may see proposals that invoke mature minor research clauses, ${ }^{4,85,88}$ which have been employed in both TGGD youth research and to aid in building trust with youth frustrated with being infantilized. ${ }^{85,88,89}$ Implementing these clauses may require a number of unique safeguards, such as the use of independent advocates to assure participants' rights. Other researchers have used innovative approaches to ensuring capacity to consent, as in Kuper's ${ }^{90}$ use of a four-item true-false questionnaire that tested comprehension of the informed consent document and blocked survey participation until it was correctly completed.

Research should align with current professional standards that refute conversion, reorientation, or reparative therapy

IRBs are advised to reject clinical research that entails conversion, reorientation, or reparative therapy. These approaches describe attempts to change an individual's sexual orientation or gender identity to align with the sex they were assigned at birth and are increasingly recognized as inherently unethical. ${ }^{91}$ A growing body of literature is highly critical of this type of therapy. ${ }^{67,91-96}$ In particular, therapies focused on encouraging TGGD children to develop into heterosexual and/or cisgender adults have been shown to cause significant distress and negative outcomes. ${ }^{18,67,97-99}$ Numerous professional bodies have echoed these concerns by issuing statements advising against or prohibiting the practice of reparative therapy, including a coalition of the United Kingdom's professional organizations and public health bodies, ${ }^{100}$ the American College of Physicians, ${ }^{101}$ the American Psychoanalytic Association, ${ }^{102}$ and WPATH. ${ }^{103}$ Some jurisdictions have also legislated against it. ${ }^{104,105}$ In addition, TGGD people appear more likely to engage in research that takes a gender affirmative approach, which affirms their gender identity and seeks to optimize access to gender-affirming care. $^{106}$

\section{IRBs should guard against the temptation}

to avoid, limit, or delay research on this subject

IRBs may attempt to defensively avoid institutional investigations or external lawsuits by discouraging and/ or placing unnecessary restrictions on research investigating controversial topics. ${ }^{88}$ This may be a particular challenge in the case of research on TGGD individuals, as this population is both extremely vul- nerable to social stigma and currently the subject of intense political and social debate. However, to ignore this topic is to do a serious disservice to the individuals affected by it and deny them research needed to improve their lives. Although some caution is justified, too much may result in obstructive processes, lengthen the time taken to approve IRB applications, discourage research into complex topics, and cause researchers to avoid controversial issues and innovative research. ${ }^{6,88}$ IRBs should, therefore, consider the risks associated with not undertaking transgender health research alongside those involved in undertaking any given project.

\section{Conclusion}

This article outlines nine provisional criteria that can be used to assess the ethical orientation of transgender health research projects. Although they are primarily intended to guide IRBs in assessing proposals before them, they may also prove useful to editors and reviewers examining research undertaken with TGGD participants, as well as individual researchers evaluating their own study designs. These criteria have been developed by the authors through reviewing, adapting, and summarizing the relevant literature on this topic. We hope that they will serve as a useful starting point for researchers considering these important issues, rather than as an exhaustive list of ethical considerations for research involving TGGD people. Although we have attempted to include authors from a diverse range of backgrounds in the creation of this article, we know that a thorough and systematic consultation with a variety of TGGD communities and individuals is needed to further develop the guidelines presented here. ${ }^{3}$

We further hope that this article will draw attention to the need for a section on ethical research standards in future versions of the WPATH Standards of Care for the Health of Transsexual, Transgender, and Gender Nonconforming People. The Standards of Care provide detailed and internationally relevant guidance for healthcare practitioners working to support TGGD people. Expanding their scope to include guidance on research standards will encourage ethically and methodologically rigorous research, particularly among clinician researchers.

\section{Acknowledgment}

The authors would like to thank Mauro Cabral for reviewing an early copy of this article for the appropriateness of language regarding intersex experiences. 


\section{Author Disclosure Statement}

No competing financial interests exist.

\section{References}

1. Bennett S, Longstaff H. Model Review: A Discussion of a Case Study and Framework to Enhance Research Ethics Review of Research Involving Gender Non-Conforming, Genderqueer, and Transgendered Youth. Paper presented at: CAREB ACCER National Conference, Toronto, ON, May 26, 2016. Available from: www.careb-accer.org/sites/default/files/ downloads/model_review.pdf (last accessed April 11, 2017).

2. Reisner SL, Poteat T, Keatley J, et al. Global health burden and needs of transgender populations: a review. Lancet. 2016;388:412-436.

3. Heinz M, Bauer G, Marshall Z, Pyne J. Ethical guidelines for research involving trans people. Symposium presented at: Canadian Professional Association for Transgender Health Conference; October 2, 2015 (cited 2017 April 11); Halifax, NS.

4. Martin Jl, Meezan W. Applying ethical standards to research and evaluations involving lesbian, gay, bisexual, and transgender populations. J Gay Lesbian Soc Serv. 2003;15:181-201.

5. Tebbe EA, Budge SL. Research with trans communities: applying a process-oriented approach to methodological considerations and research recommendation. Couns Psychol. 2016;44:1-29.

6. Gunsalus CK, Bruner EM, Burbules N, et al. The Illinois white paper: improving the system for protecting human subjects: counteracting IRB "mission creep." Qual Inq. 2007;13:1-32.

7. Miner MH, Bockting WO, Romine RS, Raman S. Conducting internet research with the transgender population: reaching broad samples and collecting valid data. Soc Sci Comput Rev. 2012;30:202-211.

8. Sevelius J, Dickey LM, Singh AA. Engaging in TGNC affirmative research. In: Affirmative Counseling and Psychological Practice with Transgender and Gender Nonconforming Clients (Perspectives on Sexual Orientation and Gender Diversity). (Singh AA, Dickey LM; eds). Washington, DC: American Psychological Association, 2017, pp. 213-246.

9. Winter S, Diamond M, Green J, et al. Transgender people: health at the margins of society. Lancet. 2016;388:390-400.

10. Cauldwell DO. Psychopathia transsexualis. Sexology. 1949;16: 274-280.

11. Green R. The 'Sissy Boy Syndrome' and The Development of Homosexuality. New Haven, CN: Yale University Press, 1987.

12. Zucker KJ, Wild J, Bradley SJ, Lowry CB. Physical attractiveness of boys with gender identity disorder. Arch Sex Behav. 1993;22:23-36.

13. Ansara YG, Hegarty P. Cisgenderism in psychology: pathologising and misgendering children from 1999-2008. Psychol Sex. 2012;3:137-160.

14. Brotman $S$, Ryan $B$, Jalbert $Y$, Rowe $B$. The impact of coming out on health and health care access: the experiences of gay, lesbian, bisexual and two-spirit people. J Health Soc Policy. 2002;15:1-29.

15. Namaste V. Invisible Lives: The Erasure of Transsexual and Transgendered People. Chicago, IL: University of Chicago Press, 2000.

16. Denny, D. The Politics of Diagnosis and a Diagnosis of Politics. Transgender Tapestry. 2002 Summer 98. Available from: http://ifge.org/ ?q=node/59 (last accessed April 11, 2017).

17. Walker P, Berger J, Green R, et al. Standards of Care: The Hormonal and Surgical Sex Reassignment of Gender Dysphoric Persons. Galveston, TX: Harry Benjamin International Gender Dysphoria Association, 1979.

18. American Public Health Association. The Need for Acknowledging Transgendered Individuals Within Research and Clinical Practice [Internet]. January 1, 1999. Available from: http://apha.org/policies-andadvocacy/public-health-policy-statements/policy-database/2014/07/ 29/09/18/the-need-for-acknowledging-transgendered-individualswithin-research-and-clinical-practice (last accessed April 11, 2017).

19. Reicherzer SL, Shavel S, Patton J. Examining research issues of power and privilege within a gender-marginalized community. J Soc Behav Health Sci. 2013;7:79-97.

20. Thom KC. 6 Ways the Healthcare Industry Needs to Stop Abusing Trans People. Everyday Feminist [Internet]. October 27, 2015. Available from: http://everydayfeminism.com/2015/10/healthcare-abusing-trans-folks (last accessed April 11, 2017).

21. Crenshaw K. Mapping the margins: intersectionality, identity politics, and violence against women of color. Stanford Law Rev. 1991;43:1241-1299.

22. Hayward ES. Don't exist. Transgender Stud Q. 2017;4:191-194.
23. McDonald C. Go beyond our natural selves: the prison letters of $\mathrm{CeCe}$ McDonald. Transgender Stud Q. 2017;4:243-265.

24. Hines S. Sexing gender; gendering sex: towards an intersectional analysis of transgender. In: Theorizing Intersectionality and Sexuality. (Taylor Y, Hines S, Casey M; eds). Basingstoke, England: Palgrave Macmillan, 2010, pp. 140-162.

25. Kunzel R. The flourishing of transgender studies. Transgender Stud Q. 2014;1:285-297.

26. Monro S, Richardson D. Intersectionality and sexuality: the case of sexuality and transgender equalities work in UK local government. In: Theorizing Intersectionality and Sexuality. (Taylor Y, Hines S, Casey M; eds). Basingstoke, England: Palgrave Macmillan, 2010, pp. 99-118.

27. Nagoshi JL, Brzuzy S. Transgender theory: embodying research and practice. Affilia. 2010;25:431-443.

28. Vidal-Ortiz S. Teaching and learning guide for transgender and transsexual studies: sociology's influence and future steps. Sociol Compass. 2008;2:433-450.

29. Vries KM. Intersectional identities and conceptions of the self: the experience of transgender people. Symb Interact. 2012;35:49-67.

30. Kevin J, Neilands TB, Sevelius J. Transgender women of color: discrimination and depression symptoms. Ethn Inequal Health Soc Care. 2013;6:121-136.

31. Siembida EJ, Eaton LA, Maksut JL, et al. Comparison of HIV-related risk factors between black transgender women and black men who have sex with men. Transgender Health. 2016;1:172-180.

32. Singh AA. Transgender youth of color and resilience: negotiating oppression and finding support. Sex Roles. 2013;68:11-12.

33. Dutta A. Between Aid Conditionality and Identity Politics - The MSMTransgender Divide and Normative Cartographies of gender vs. Sexuality [Internet]. Kafila. April 4, 2012. Available from: https:// kafila.online/2012/04/05/between-aid-conditionality-and-identitypolitics-the-msm-transgender-divide-and-normative-cartographies-ofgender-vs-sexuality-aniruddha-dutta (last accessed July 22, 2017).

34. Thompson $\mathrm{H}$. Who counts as "Transgender"? Epidemiological methods and a critical intervention. Transgender Stud Q. 2015;2:148-159.

35. Bouman WP, Schwend AS, Motmans J, et al. Language and trans health. Int J Transgend. 2016;18:1-6.

36. Pearce R. (Im)possible Patients: Discourses of Trans Health in the UK [dissertation]. Coventry, England: University of Warwick, 2016.

37. Serano J. Considering Trans and Queer Appropriation [Internet]. October 1, 2013. Available from: http://juliaserano.blogspot.be/2013/10/ considering-trans-and-queer.html (last accessed April 11, 2017).

38. Monro S. Towards a sociology of gender diversity. In: Transgender Identities: Towards a Social Analysis of Gender Diversity. (Hines S, Sanger T; eds). New York: Routledge, 2010, pp. 242-258.

39. Jarrín A. Untranslatable subjects: travesti access to public health care in Brazil. Transgender Stud Q. 2016;3:357-375.

40. Roen K. Transgender theory and embodiment: the risk of racial marginalisation. J Gender Stud. 2001;10:253-263.

41. Singer BT. The profusion of things: the "transgender matrix" and demographic imaginaries in US public health. Transgender Stud Q. 2015;2:58-76.

42. Dickey LM, Hendricks ML, Bockting WO. Innovations in research with transgender and gender nonconforming people and their communities. Psychol Sex Orientat Gend Divers. 2016;3:187-194.

43. Singh AA, Richmond K, Burnes TR. Feminist participatory action research with transgender communities: fostering the practice of ethical and empowering research designs. Int J Transgend. 2013;14:93-104.

44. Deutsch MB, Radix A, Reisner S. What's in a guideline? Developing collaborative and sound research designs that substantiate best practice recommendations for transgender health care. AMA J Ethics. 2016;18:1098-1106.

45. Bettinger TV. Ethical and methodological complexities in research involving sexual minorities. New Horizons Adult Educ Hum Resour Dev. 2010;24:43-58.

46. Bonevski B, Randell M, Paul C, et al. Reaching the hard-to-reach: a systematic review of strategies for improving health and medical research with socially disadvantaged groups. BMC Med Res Methodol. 2014;14:1-29.

47. Horvath KJ, lantaffi A, Grey JA, Bockting W. A review of the content and format of transgender-related webpages. Health Commun. 2012;27:457-466. 
48. Seshia M. The Unheard Speak Out: Street Sexual Exploitation in Winnipeg. Ottawa, Canada: Canadian Centre for Policy Alternatives, 2005. Available from: https://policyalternatives.ca/sites/default/files/.../ The_Unheard_Speak_Out.pdf (last accessed April 11, 2017).

49. Beemyn G, Rankin S. The Lives of Transgender People. New York: Columbia University Press, 2011.

50. Galupo MP. Researching while cisgender: identity considerations for transgender research. Int J Transgend. 2017;18:1-2.

51. Moon L. The gentle violence of therapists: misrecognition and dislocation of the other. Psychother Polit Int. 2011;9:194-205.

52. Ansara YG, Hegarty P. Methodologies of misgendering: recommendations for reducing cisgenderism in psychological research. Fem Psychol. 2014;24:259-270.

53. Bauer GR, Hammond R. Toward a broader conceptualization of trans women's sexual health. Can J Hum Sex. 2015:24:1-11.

54. Bauer GR. Making sure everyone counts: considerations for inclusion, identification and analysis of transgender and transsexual participants in health surveys. In: What a Difference Sex and Gender Make: A Gender, Sex and Health Research Casebook. (Canadian Institutes of Health Research Institute of Gender and Health; eds). Vancouver, Canada: CIHR Institutes of Gender and Health, 2012, pp. 59-68.

55. Tannehill B. How Research is Used to Support the Legal Marginalization of Transgender People. Symposium presented at: The World Professional Association for Transgender Health Conference, Amsterdam, The Netherlands, June 21, 2016. Available from: http:// brynntannehill.com/wp-content/uploads/2016/06/How-Research-isBeing-MisUsed-to-Support.pptx (last accessed April 11, 2017).

56. Dhejne C, Lichtenstein P, Bouman M, et al. Long-term follow-up of transsexual persons undergoing sex reassignment surgery: cohort study in Sweden. PLoS One. 2011;6:1-8.

57. Lawrence AA. Men trapped in men's bodies: narratives of autogynephilic transsexualism. New York: Springer, 2013.

58. Steensma TD, Biemond R, de Boer F, Cohen-Kettenis PT. Desisting and persisting gender dysphoria after childhood: a qualitative follow-up study. Clin Child Psychol Psychiatry. 2011;16:499-516.

59. Karasic DH. Views about transgendered that are stuck in the past [Internet]. Wall Street J. June 18, 2014. Available from: https://wsj.com/ articles/views-about-transgendered-that-are-stuck-in-the-past1403122012 (last accessed April 11, 2017).

60. Williams C. Fact Check: Study Shows Transition Makes Trans People Suicidal [Internet]. The Trans Advocate. November 14, 2015. Available from: http://transadvocate.com/fact-check-study-shows-transitionmakes-trans-people-suicidal_n_15483.htm (last accessed April 11، 2017)

61. Feinberg L. Trans health crisis: for us it's life or death. Am J Public Health. 2001;91:897-900.

62. Organisation Intersex International Australia. Including Intersex in Research Studies and Surveys [Internet]. May 25, 2012. Available from: https://oii.org.au/20042/on-requests-for-research (last accessed April 11, 2017).

63. Travers R, Pyne J, Bauer G, et al. 'Community control' in CBPR: challenges experienced and questions raised from the Trans PULSE project. Action Res. 2013;11:403-422.

64. Rainbow Health Ontario. Rainbow Health Ontario Website [Internet]. Available from: http://rainbowhealthontario.ca/resource-type/video (last accessed April 11, 2017).

65. Chang $E$, Simon $M$, Dong $X$. Integrating cultural humility into health care professional education and training. Adv Health Sci Educ. 2012;17:269-278.

66. World Health Organization. Indigenous Peoples and Participatory Health Research. Geneva, Switzerland: World Health Organization, 2003.

67. Hird MJ. A typical gender identity conference? Some disturbing reports from the therapeutic front lines. Fem Psychol. 2003;13:181-199.

68. Gramling D, Dutta A. Introduction. Transgender Stud Q. 2016;3:333-356.

69. Bockting W. Transforming the paradigm of transgender health: a field in transition. Sex Relation Ther. 2009;24:103-107.

70. Constant A. Examining the Term Transgender in Attitude Studies [Thesis]. Bridgewater, MA: Bridgewater State University, 2016.

71. The GenIUSS Group. Best Practices for Asking Questions to Identify Transgender and Other Gender Minority Respondents on Population-based Surveys. Los Angeles, CA: The Williams Institute, 2014.
72. Xavier J, Honnold JA, Bradford J. The Health, Health-Related Needs, and Life Course Experiences of Transgender Virginians. Richmond, VA: Virginia HIV Community Planning Committee and Virginia Department of Health, 2007.

73. Sausa LA, Sevelius J, Keatley, J, et al. Recommendations for Inclusive Data Collection of Trans People in HIV Prevention, Care and Services [Internet]. San Francisco, CA: Center of Excellence for Transgender Health, 2009. Available from: http://transhealth.ucsf.edu/trans?page= lib-data-collection (last accessed April 11, 2017).

74. Reisner SL, Biello K, Rosenberger JG, et al. Using a two-step method to measure transgender identity in Latin America/the Caribbean, Portugal, and Spain. Arch Sex Behav. 2014;43:1503-1514.

75. Grant JM, Mottet LA, Tanis J, et al. Injustice At Every Turn: A Report of the National Transgender Discrimination Survey [Internet]. Washington, DC: National Center for Transgender Equality and National Gay and Lesbian Task Force, 2011. Available from: http://thetaskforce.org/static_html/ downloads/reports/reports/ntds_full.pdf (last accessed April 11, 2017).

76. Heinz M, MacFarlane D. Island lives: a trans community needs assessment for Vancouver Island. SAGE Open. 2013;3:1-13.

77. Organisation Intersex International Australia. Intersex People and Identification Documents [Internet]. January 20, 2014. Available from: https://oii.org.au/24378/intersex-people-and identification documents/ (last accessed April 11, 2017).

78. Harrison J, Grant JM, Herman JL. A gender not listed here: genderqueers, gender rebels, and otherwise in the National Transgender Discrimination Survey. LGBTQ Policy J Harvard Kennedy School. 2012;2:13-24.

79. Smith $\mathrm{E}$, Jones $\mathrm{T}$, Ward R, et al. From Blues to Rainbows: Mental Health and Wellbeing of Gender Diverse and Transgender Young People in Australia. Melbourne, Australia: The Australian Research Centre in Sex, Health, and Society, 2014.

80. American Psychological Association. Guidelines for psychological practice with transgender and gender nonconforming people. Am Psychol. 2015;70:832-864.

81. European Union Agency for Fundamental Rights. Professionally Speaking: Challenges to Achieving Equality for LGBT People. Luxembourg, Europe: Publications Office of the European Union, 2016.

82. Cooper MA. Hormone treatment clinic for transsexuals. Hawaii Med J. 1987;43:142-146.

83. Kristen PH. 'I want the world to know': the ethics of anonymity in ethnographic literacy research. In: Methodological Developments in Ethnography (Studies in Educational Ethnography). (Walford G; ed). Amsterdam, The Netherlands: Elsevier, 2007, pp. 137-154.

84. Saunders B, Kitzinger J, Kitzinger $C$. Anonymising interview data: challenges and compromise in practice. Qual Res. 2014;15:616-632.

85. Taylor C. Counterproductive effects of parental consent in research involving LGBTTIQ youth: international research ethics and a study of a transgender and Two-Spirit community in Canada. J LGBT Youth. 2008;5:34-56.

86. D'Augelli AR, Grossman AH. Researching lesbian, gay and bisexual youth: conceptual, practical, and ethical considerations. J Gay Lesbian Issues Educ. 2006;3:35-56.

87. Fisher $C B$, Mustanski $B$. Reducing health disparities and enhancing the responsible conduct of research involving LGBT youth. Hastings Cent Rep. 2014;44:S28-S31.

88. Sanders JH, Ballengee-Morris C. Troubling the IRB: institutional review boards' impact on art educators conducting social science research involving human subjects. Stud Art Educ. 2008;49:311-327.

89. Grossman AH, Haney AP, Edwards $P$, et al. Lesbian, gay, bisexual and transgender youth talk about experiencing and coping with school violence: a qualitative study. J LGBT Youth. 2009;6:24-47.

90. Kuper LE. Gender Development and Suicidality Among Transgender and Gender Non-Conforming Youth and Young Adults [Dissertation]. Chicago, IL: University of Illinois at Chicago, 2015.

91. Reitman DS, Austin B, Belkind U, et al. Recommendations for promoting the health and well-being of lesbian, gay, bisexual, and transgender adolescents: a position paper of the Society for Adolescent Health and Medicine. J Adolesc Health. 2013;52:506-510.

92. Bryant K. In defense of gay children? 'Progay' homophobia and the production of homonormativity. Sexualities. 2008;11:455-475.

93. Bryant K. Making gender identity disorder of childhood: historical lessons for contemporary debates. Sex Res Social Policy. 2006; 3:23-39. 
94. Hein LC, Berger KC. Gender dysphoria in children: let's think this through. J Child Adolesc Psychiatr Nurs. 2012;25:237-240.

95. Langer SJ, Martin Jl. How dresses can make you mentally ill: examining gender identity disorder in children. Child Adolesc Social Work J. 2004;21:5-23.

96. Pickstone-Taylor SD. Letters to the editor: children with gender nonconformity. J Am Acad Child Adolesc Psychiatry. 2003;42:266-268.

97. Hill DB, Rozanski C, Carfagnini J, Willoughby B. Gender identity disorders in childhood and adolescence: a critical inquiry. J Psychol Human Sex. 2006;17:7-34.

98. Pyne J. The governance of gender non-conforming children: a dangerous enclosure. Annu Rev Clin Psychol. 2014;11:79-96.

99. Pyne J. Commentary: gender independent kids: a paradigm shift in approaches to gender non-conforming children. Can J Hum Sex. 2014;23:1-8.

100. The British Association for Counselling and Psychotherapy, The British Association for Behavioural and Cognitive Psychotherapies, The British Psychoanalytic Council et al. UK Organisations Unite Against Conversion Therapy. UK Organizations Unite Against Conversion Therapy [Internet]. London, England: Royal College of General Practitioners, January 16, 2017. Available from: http://rcgp.org.uk/news/2017/january/ uk-organisations-unite-against-conversion-therapy.aspx (last accessed April 11, 2017)

101. Daniel H, Butkus R. Lesbian, gay, bisexual, and transgender health disparities: executive summary of a policy position paper from the American College of Physicians. Ann Intern Med. 2015;163:135-137.

102. American Psychoanalytic Association. Position Statement on Attempts to Change Sexual Orientation, Gender Identity, or Gender Expression [Internet]. New York: American Psychoanalytic Association, June 2012. Available from: http://apsa.org/content/2012-position-statementattempts-change-sexual-orientation-gender-identity-or-gender (last accessed April 11, 2017).
103. Coleman E, Bockting W, Botzer M, et al. Standards of Care for the Health of Transsexual, Transgender, and Gender-Nonconforming People (7th Version). Minneapolis, MN: World Professional Association for Transgender Health, 2012.

104. New York State. Governor Cuomo Announced Executive Actions Banning Coverage of Conversion Therapy [Internet]. Febuary 6, 2016. Available from: https:/governor.ny.gov/news/governor-cuomoannounces-executive-actions-banning-coverage-conversion-therapy (last accessed April 11, 2017).

105. Affirming Sexual Orientation and Gender Identity Act, Bill 77, 41st Parl., 1st Sess. (2015)

106. Reisner SL, Radix A, Deutsch MB. Integrated and gender-affirming transgender clinical care and research. J Acquir Immune Defic Syndr. 2016;72(Suppl 3):S235-S242.

Cite this article as: Adams N, Pearce R, Veale J, Radix A, Castro D, Sarkar A, Thom KC (2017), Guidance and ethical considerations for undertaking transgender health research and institutional review boards adjudicating this research, Transgender Health 2:1, 165-175, DOI: $10.1089 /$ trgh.2017.0012.

\section{Abbreviations Used}

IRB = Institutional Review Board

TGGD $=$ transgender and gender diverse

TGNC $=$ transgender and gender nonconforming

WPATH $=$ World Professional Association for Transgender Health

\section{Appendix 1: Terms for Transgender Health Research}

\section{Cisgender}

A "cis/cisgender/cisperson, [is] a person whose gender identity is the same as the sex they were assigned at birth."A1

\section{Cisgenderism}

The prioritization of non-transgender and gender diverse (TGGD) identities as "healthy or ideal... [This term] describes a prejudicial ideology...that is; systemic, multi-level and reflected in authoritative cultural discourses... [demonstrating] that such categorical distinctions can themselves be" prejudicial. ${ }^{\mathrm{A} 2}$

\section{Gender Identity}

This term describes an individual's internal sense of themselves as male, female, both, neither, or some other permutation. This is distinct from sex, which refers to the physiological sex characteristics present in an individual at their birth.

\section{Gender Incongruence}

Gender incongruence is the feeling, held by some TGGD individuals, that one's sex assigned at birth and gender identity are misaligned. This feeling may extend to a desire "to have been born the other sex, or the desire to change sex." $\mathrm{A} 3$

\section{Gender Diverse}

This term may describe individuals who do not identify as completely male or female and who may use descriptors such as non-binary, genderqueer, butch, and/or transgender; individuals who express gender nonconformity but do not necessarily ascribe to a transgender identity; and/or individuals whose gender identities do not align with either the female/male binary or the white, Western cultural context of transgender.

\section{Intersex}

Intersex is a term that encompasses a number of medical conditions where an individual "is born with... reproductive or sexual anatomy that doesn't fit the typical definitions of female or male." This may manifest as elements of male and female anatomy in a single individual, or a potentially more invisible inconsistency of chromosomal sex. ${ }^{\mathrm{A} 4}$ 


\section{Transition}

Transition is typically defined as the time when an individual begins to live as a new gender that is different from the sex they were assigned at birth. This process usually starts with changing one's name and documents to reflect the new gender and may include hormones and surgery to make the individual's body more closely match that of the gender to which they are transitioning. ${ }^{\text {A5 }}$

\section{Transgender}

Depending on cultural and geographic context, transgender may be seen as a gender identity that denotes a desire to live in a gender role different from that assigned at birth, and/or "an umbrella term which includes transsexuals, cross dressers, intersex... persons, gender variant persons and many [others that may or may not have] ... undergone any surgery or physiological changes." ${ }^{\mathrm{A} 6}$

\section{Transsexual}

This term has historically described individuals who feel that "their inner sense of being male or female [fundamentally] conflicts... with [their] biological sex... [These individuals] have taken or want to take measures (surgery or hormones, etc.) to permanently change their physical sex." ${ }^{\text {A7 }}$ In recent years, it has become more common for the term to be used by and for individuals of any gender who have or intend to permanently transition socially and/or physically.

\section{Two-Spirit/ed}

This is "an umbrella term... [that is sometimes used by] aboriginal individuals who live between socially defined male and female gender roles." ${ }^{\mathrm{A} 8}$

\section{References}

A1. McNeil J, Bailey L, Ellis S, et al. Trans Mental Health Study 2012 [Internet] Edinburgh, United Kingdom: Scottish Transgender Alliance, 2012. Available from: https://gires.org.uk/assets/Medpro-Assets/ trans_mh_study.pdf (last accessed April 11, 2017).

A2. Ansara YG, Hegarty P. Cisgenderism in psychology: pathologising and misgendering children from 1999-2008. Psychol Sex. 2012;3: 137-160.

A3. Bockting W. Transforming the paradigm of transgender health: a field in transition. Sex Relation Ther. 2009;24:103-107.

A4. McNeil J, Bailey L, Ellis S, Regen M. Speaking from the Margins: Trans Mental Health and Wellbeing in Ireland [Internet]. Dublin, Ireland: Transgender Equality Network Ireland, 2013. Available from: http:// teni.ie/attachments/fb1627f8-fd4e-4a0a-b4d9-2aaa15cc32d4.pdf (last accessed April 11, 2017).

A5. Grant JM, Mottet LA, Tanis J, et al. Injustice At Every Turn: A Report of the National Transgender Discrimination Survey [Internet]. Washington, DC: National Center for Transgender Equality and National Gay and Lesbian Task Force, 2011. Available from: http://thetaskforce.org/ static_html/downloads/reports/reports/ntds_full.pdf (last accessed April 11, 2017).

A6. Laxmi T, Gauri S, Payal K, et al. Transgender: hijra strategy [Internet]. New Delhi, India: National AIDS Control Organisation, and National AIDS Control Program IV, May 5, 2011. Available from: http://naco.gov.in/sites/ default/files/4.\%20TG_paper_NACO\%20shortversion.pdf (last accessed April 11, 2017).

A7. Taylor C. Nowhere Near Enough: A Needs Assessment of Health and Safety Services for Transgender and Two Spirit People in Manitoba and Northwestern Ontario [Internet]. Winnipeg, Canada: Crime Prevention Branch Public Safety and Emergency Preparedness Canada, 2006. Available from: http://turtleisland.org/discussion/viewtopic.php? $p=7927$ (last accessed April 11, 2017)

A8. Scheim Al, Jackson R, James $L$, et al. Barriers to well-being for aboriginal gender diverse people: Results from the trans PULSE project in Ontario, Canada. Ethn Inequal Health Soc Care. 2013;6:106-120.

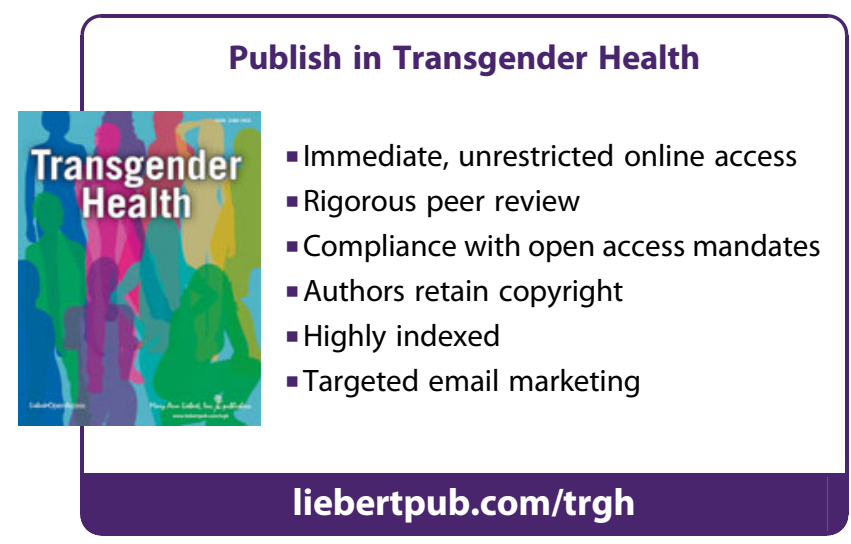

